\title{
南海台西南盆地自生管状黄铁矿中纳米级石墨碳的发现 及其对天然气水合物的示踪意义
}

张美 ${ }^{(1)}$, 孙晓明 ${ }^{(12) * *}$, 徐莉 ${ }^{(2)}, \mathrm{XU} \mathrm{HuiFang}^{(4)}, \mathrm{KONISHI} \mathrm{Hiromi}{ }^{(4)}$, 芦阳 ${ }^{(1)}$, 陆红锋 ${ }^{(5)}$, 吴仲玮 ${ }^{(1)}$

(1) 中山大学地球科学系, 广州 510275;

(2) 中山大学海洋学院, 广州 510275 ;

(3) 广东省海洋资源与近岸工程重点实验室, 广州 510275;

(4) Department of Geosciences, University of Wisconsin, Madison WI, 53706, USA;

(5) 国土资源部广州海洋地质调查局, 广州 510760

* 联系人, E-mail: eessxm@mail.sysu.edu.cn

2010-12-30 收稿, 2011-04-18 接受

天然气水合物资源勘查与试采工程国家专项(GZH201100305-06-06)、高等学校博士学科点专项科研基金(20090171120019)、中央高校基本 科研业务费专项资金(09lgpy09)和中国科学院边缘海地质重点实验室开放研究基金(MSGL08-01, MSGLCAS03-4)资助

摘要 海底天然气水合物是十分重要的能源矿产, 目前主要是根据似海底反射面(BSR)等地 球物理方法和海底地球化学异常示踪其存在.此外, 与天然气水合物有关的自生矿物如碳酸 盐、硫酸盐和硫化物等矿物也是重要的示踪体系。本文利用扫描电子显微镜(SEM)和高分辨率 透射电子显微镜(HRTEM), 对来自南海台西南盆地沉积物中的自生管状黄铁矿进行了系统的 观测, 发现它们主要由草莓状黄铁矿组成, 且在草莓状黄铁矿中首次发现了纳米级的低结晶度 石墨碳, 它们主要呈现出似纳米碳管和纳米锥形状, 而且与黄铁矿密切共生, 显示它们可能主 要形成于含 $\mathrm{C}$ 过饱和 $\mathrm{C}-\mathrm{H}-\mathrm{O}$ 流体的沉淀. 黄铁矿在 $\mathrm{CH}_{4}$ 转变为原子 $\mathrm{C}$ 的过程中起催化作用. 自生管状黄铁矿中新发现的纳米级石墨碳, 显示其沉积时沉积岩围岩中存在 $\mathrm{CH}_{4}$ 过饱和流体, 因此可作为天然气水合物又一重要示踪矿物。此外，低温环境中纳米石墨碳的发现对石墨的实 验室合成和工业生产等有借鉴意义.

天然气水合物是一种赋存在高压低温条件下、主 要由甲烷和水分子构成的非化学计量结晶物质 ${ }^{[1]}$. 作 为近二十多年来发现的一种新型超洁净能源，天然 气水合物在能源勘探、海底灾害环境和全球气候变化 研究中的日益重要性已逐渐引起世界各国的高度重 视. 由于其主要分布在水深 300 3000 m 的陆架斜坡 和深海盆地沉积物内, 迄今为止, 除海底钻探和深海 沉积物取样业已获取少量海底天然气水合物样品外, 世界各地绝大多数天然气水合物的分布是通过地质、 地球物理和地球化学等方法间接确定的.

黄铁矿是大陆边缘海相沉积物中普遍存在的自 生矿物, 是沉积物发生缺氧硫酸盐还原作用的产物,
记录了沉积环境的变化，也是早期成岩作用的重点 研究对象. 正常的海相沉积物中, 有机质参与缺氧硫 酸盐还原是黄铁矿形成的第一步(式(1)), 而在天然 气水合物的沉积环境中, 普遍存在甲烷厌氧氧化过 程，同样有利于黄铁矿的形成(式(2)).

$$
\begin{gathered}
2 \mathrm{CH}_{2} \mathrm{O}+\mathrm{SO}_{4}{ }^{2-} \rightarrow \mathrm{H}_{2} \mathrm{~S}+2 \mathrm{HCO}_{3}{ }^{-} \\
\mathrm{CH}_{4}+\mathrm{SO}_{4}{ }^{2-} \rightarrow \mathrm{HCO}_{3}{ }^{-}+\mathrm{HS}^{-}+\mathrm{H}_{2} \mathrm{O}
\end{gathered}
$$

Sassen 等人 ${ }^{[2]}$ 在研究墨西哥湾北部陆坡水合物 区时, 发现大量棒状或管状以及莓球状黄铁矿, 认为 是由于硫酸盐还原带发生强烈细菌厌氧氧化作用, 产生大量 $\mathrm{HS}^{-}$的结果, 当有游离 $\mathrm{Fe}$ 离子的时候, 就产 生黄铁矿, 并且取代贝氏硫细菌属(Beggiatoa), 形成 
棒状或管状黄铁矿; 黄奇瑜等人 ${ }^{[3]}$ 在研究台湾西南海 域沉积物中黄铁矿产状时, 认为管状黄铁矿是甲烷 气体自沉积物深部向上排溢的微小通道; 陆红锋等 人 ${ }^{[4]}$ 的研究显示南海台西南盆地沉积物中自生黄铁 矿的含量变化与沉积物孔隙水中 $\mathrm{CH}_{4}$ 和 $\mathrm{SO}_{4}{ }^{2-}$ 浓度变 化具有较为密切的成因联系, 同时还受有机碳含量 变化的影响. 但到目前为止, 对于自生黄铁矿本身产 出特征与天然气水合物之间的成因联系, 尚缺乏直 接、有力的证据.

最近, 作者通过场发射扫描电子显微镜(FESEM) 和高分辨率透射电子显微镜(HRTEM), 对南海台西 南沉积物中的自生管状黄铁矿进行了较系统的矿物 学特征研究, 发现这些管状黄铁矿主要由草葋状黄 铁矿组成, 且在草莺状黄铁矿内部发现了低结晶度 纳米级石墨碳, 并针对其对天然气水合物的示踪意 义进行了初步探讨.

\section{1 研究区地质概况}

南海是西太平洋最大的边缘海之一, 位于欧亚 板块、太平洋板块和印度洋板块的交汇处. 南海的地 质构造受三大板块相互运动所制约, 形成独特的边 缘构造特征 ${ }^{[5]}$. 自中生代以来, 南海经历了一系列构 造运动, 发育富含有机质的众多盆地及台地, 具有形 成天然气水合物的充足物源和水合物成藏的有利场 所 ${ }^{[6-8]}$. 南海台西南区域就是在这样一种大构造背景 下形成的一套复杂构造沉积框架: 该区域西北边缘 由 1 3 $\mathrm{km}$ 厚的被动陆源沉积物组成; 东部边缘为主 动碰撞边缘, 由主动陆缘弧前海沟沉积和受挤压的 Heng-Ch'un 海脊叠瓦状沉积构成; 两者的交汇处形 成主动和被动陆缘侵蚀区, 主动陆缘沉积侵蚀在被 动陆缘之上 ${ }^{[9]}$. 台湾南部的构造主要受沿火山弧外侧 新增生楔的碰撞作用控制, 洋壳的沉降和俯冲作用 导致弧前海沟被厚的沉积物充填, 在逆冲变形带西 侧发育 ${ }^{[9]}$. 台西南增生楔的沉积物中等变形, 西倾不 对称的背斜被东倾的叠瓦状逆冲断层所圈闭 ${ }^{[10]}$. 已 有的研究表明, 在台西南海域存在 3 个天然气水合物 远景区,它们具有相似的构造、地层特征, 并在水深 $1 \sim 3.5 \mathrm{~km}$ 处最有利于形成天然气水合物 ${ }^{[9]}$. 目前, 在 南海海域已发现与天然气水合物有关的多种证据, 并圈定了多处天然气水合物潜在海域 ${ }^{[7,11 ~ 13]}$, 而且在 神狐海区海底下约 $200 \mathrm{~m}$ 深的沉积物中成功钻取到 天然气水合物样品 ${ }^{[14]}$.

\section{2 样品与分析方法}

本次研究的样品来自 2004 年广州海洋地质调查 局“海洋四号”和德国“太阳号”调查船 SO-177 航次采 用重力活塞取样器所获得的沉积物岩芯 $\mathrm{GC} 10$ 站位 $\left(21.3^{\circ} \mathrm{N}, 119.19^{\circ} \mathrm{E}\right.$; 图 1$)$, 岩芯位置位于南海东北部 靠近台湾岛的陆坡坡脚，站位水深 $3008 \mathrm{~m}$, 柱长 973 $\mathrm{cm}$. 在中德合作 SO-177 航次期间, “太阳号”调查船 在该区首次发现了甲烷菌席生物群落和双壳类生物 遗迹, 有的测站还发现了甲烷喷流形成的碳酸盐岩 烟图 ${ }^{[16]}$, 似海底反射层(BSR)的存在也显示该区可能 有大量的水合物存在 ${ }^{[17]}$. 样品自航次调查归岸后保 存在 $4^{\circ} \mathrm{C}$ 以下的冷冻库里. 从岩芯样品顶部开始, 按 $20 \mathrm{~cm}$ 的间隔进行取样, 将沉积物岩芯分为许多等 份, 每等份的干重为 $7.00 \mathrm{~g}$, 然后分别把每份样品置 于粒径 $0.063 \mathrm{~mm}$ 的篮子中用蒸馏水进行清洗, 将黏 土等组分冲洗干净, 余下碎屑部分(矿物和生物体)即 为包含黄铁矿的样品. 南海台西南盆地沉积物碎屑 中自生黄铁矿多为长条状、圆粒状和充填有孔虫房室

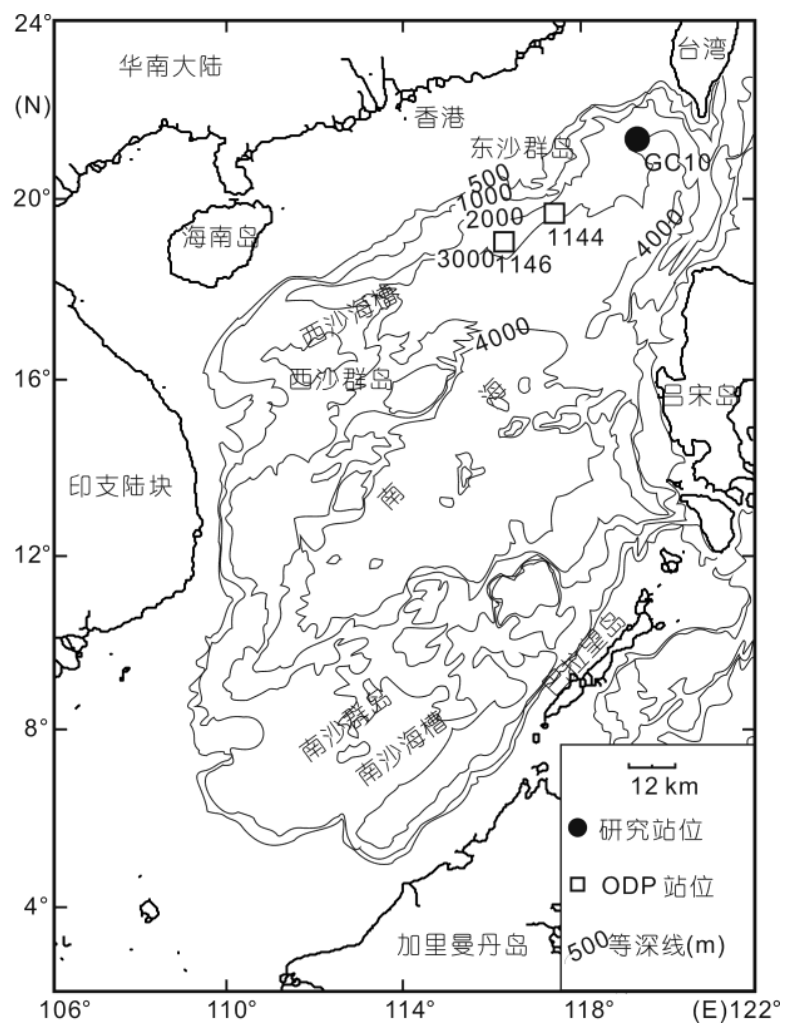

图 1 南海台西南的区域位置图 据文献[15]修改. 图中圆黑点为 $\mathrm{GC} 10$ 钻孔所在位置 
的外形, 其中长条状外形比较常见, 长度在 $0.10 \sim$ $6.00 \mathrm{~mm}$ 之间, 外直径大小比较均匀, 集中在 $0.25 \sim$ $0.30 \mathrm{~mm}$ 之间, 条状黄铁矿主要包括中空管状和实心 棒状两种类型. 管状黄铁矿内部具有明显的圈层构 造: 内部由莓球状黄铁矿组成; 中间由近似五角十 二面体莓球状黄铁矿紧密堆积而成; 外部是疏松的 黄铁矿和碎屑物 ${ }^{[18]}$.

通过实体显微镜, 从 GC10 钻孔沉积物碎屑中仔 细挑选出自生管状黄铁矿个体进行扫描电子显微镜 (SEM) 和高分辨率透射电子显微镜 (HRTEM) 的分析. 扫描电子显微镜形貌分析的样品是直接把黄铁矿个 体散布在导电胶上进行观察的. 该分析在美国威斯 康星大学材料科学中心完成, 所用仪器采用美国 FEI 公司制造的 Quanta400 型扫描电子显微镜(SEM)和美 国 EDAX 公司生产的 Genesis X 射线能谱仪. 主要技 术指标为, Quanta400 型扫描电子显微镜, 高压 $20 \mathrm{kV}$; 分辨率 $3.0 \mathrm{~nm}$; 放大倍数 20 100000 倍; HRTEM 样 品的制备过程如下：首先将研碎的样品分散于乙醇 中, 制成悬浮液, 取 1 滴置于带孔的方华膜微栅上, 静置待干后即得. HRTEM 分析在美国威斯康星大学 材料科学中心完成, 所用仪器为带 SAED(Selected Area Electron Diffraction Pattern)的 TEM. 其中, TEM 电子显微镜型号为 Philips CM200 UT 场发射透射电 子显微镜, $\mathrm{LaB}_{6}$ 灯丝, 球面相差 $(\mathrm{Cs})$ 为 $0.5 \mathrm{~mm}$, 点分 辨率为 $0.19 \mathrm{~nm}$. 能谱仪(EDS)为 NORAN Voyager, 加速电压为 $200 \mathrm{kV}$.

\section{3 结果与讨论}

\section{1 扫描电子显微镜(SEM)分析结果}

扫描电子显微镜结果显示台西南盆地中的管状 黄铁矿主要由莓球状黄铁矿组成(图 2(a), (b), (d)), 在 管内部, 草莓状黄铁矿主要是由八面体黄铁矿堆积 而成(图 2(d)); 在管壁中间致密层, 草莓状黄铁矿由 核部和外壳组成, 核部主要由无数的球粒微晶紧密 堆积而成, 整个草莓状黄铁矿呈五角十二面体的外 形紧密堆积组成管壁(图 2(b)). 在管状黄铁矿中还夹 杂一些石英、硅酸盐矿物和后期沉淀的硫酸盐矿物. 扫描电子显微镜能谱(EDS)谱图显示, 黄铁矿晶体内 含有 $\mathrm{C}$ 元素(图 2(f)). 在莓球状黄铁矿表面, 依附生 长着丝状物(图 2(c)), 其主要成分为碳(图 2(e)), 推测 为生物遗体.

\section{2 高分辨率透射电子显微镜(HRTEM)观测结果}

用高分辨率透射电子显微镜观测草莓状黄铁矿 样品, 在其中发现一种纳米级的石墨碳(图 3), 从其 电子衍射花样图 (SAED)上较弱的衍射斑点可知 (图 3(e)), 这些石墨的结晶程度应很低. 此外, 从图 3(e) 还可以看出, 除了明显的石墨衍射环外, 还存在几个 明显的衍射点, 这可能是黄铁矿产生的衍射点. 该区 的 EDS 图谱(图 3(d)) 显示, 除了明显的 C 特征峰外, 还可见较小的 $\mathrm{Cu}, \mathrm{S}, \mathrm{Fe}$ 特征峰, 其中 $\mathrm{Cu}$ 来自于铜网, $\mathrm{S}$ 和 $\mathrm{Fe}$ 是样品中的黄铁矿的两个元素, 这也说明了 石墨碳与黄铁矿的密切共生关系.

图 4 为草莓状黄铁矿中共生的各种形态的纳米 级石墨碳 HRTEM 照片, 从图 4 可以看出, 有似碳纳 米层状和纳米雉形状(图 4(f)), 其中似纳米管状包括 环状(图 4(a) (c), (e))和板状(图 4(d)和(e))两种形态. 环状结构者直径多为 10 20 nm, 在部分环状石墨碳 中, 有些呈多边形, 主要由几层石墨层组成; 板状者 (图 4(d))一般由 2 10 层石墨碳组成, 最大的直径高达 $20 \mathrm{~nm}$; 具雉形状结构者为中空, 长为 $58.19 \mathrm{~nm}$, 底 部最宽为 $8.71 \mathrm{~nm}$, 由 4 层石墨碳组成. 锥形石墨的 微结构与碳纳米管十分相似, 同样由共轴的圆柱形 石墨层构成, 但该石墨层由内到外长度逐渐增加, 构 成雉形结构, 因而不同于碳纳米管石墨层所具有的 等长特征. 值得注意的是, 前人所报道的石墨矿中发 现的微纳米尺寸锥形石墨碳与本次研究发现的黄铁 矿中石墨雉在结构上较为相似, 同样是由圆雉形的 石墨层(套)构成的 ${ }^{[19]}$.

\section{3 讨论}

大陆边缘海环境中, 大量的陆源物质被河流带 人海洋, 沿大陆边缘沉淀堆积, 同时也将大量的有机 质沉积下来(如富含有机质的南海台西南盆地). 在缺 氧环境下, 硫酸盐还原作用和持久的埋藏作用是海 洋沉积物中有机质的两种主要归宿 ${ }^{[20]}$. 在沉积物深 部的还原环境中, 有机质通常在产甲烷细菌的作用 下降解而形成 $\mathrm{CH}_{4}, \mathrm{CO}_{2}$ 和 $\mathrm{H}_{2}$ 等挥发分. 此外, 作为 有机质或含碳物质变质沉淀的产物, 天然石墨碳也 通常形成于一种缺氧还原的沉积环境. 含碳物质的 变质作用和含 $\mathrm{C}-\mathrm{H}-\mathrm{O}$ 流体的沉淀作用则被认为是岩 石中石墨形成的两种主要过程 ${ }^{[21]}$ : 一种是由沉积物 中有机碳变质而原地沉淀, 一般呈分散的石墨薄层 

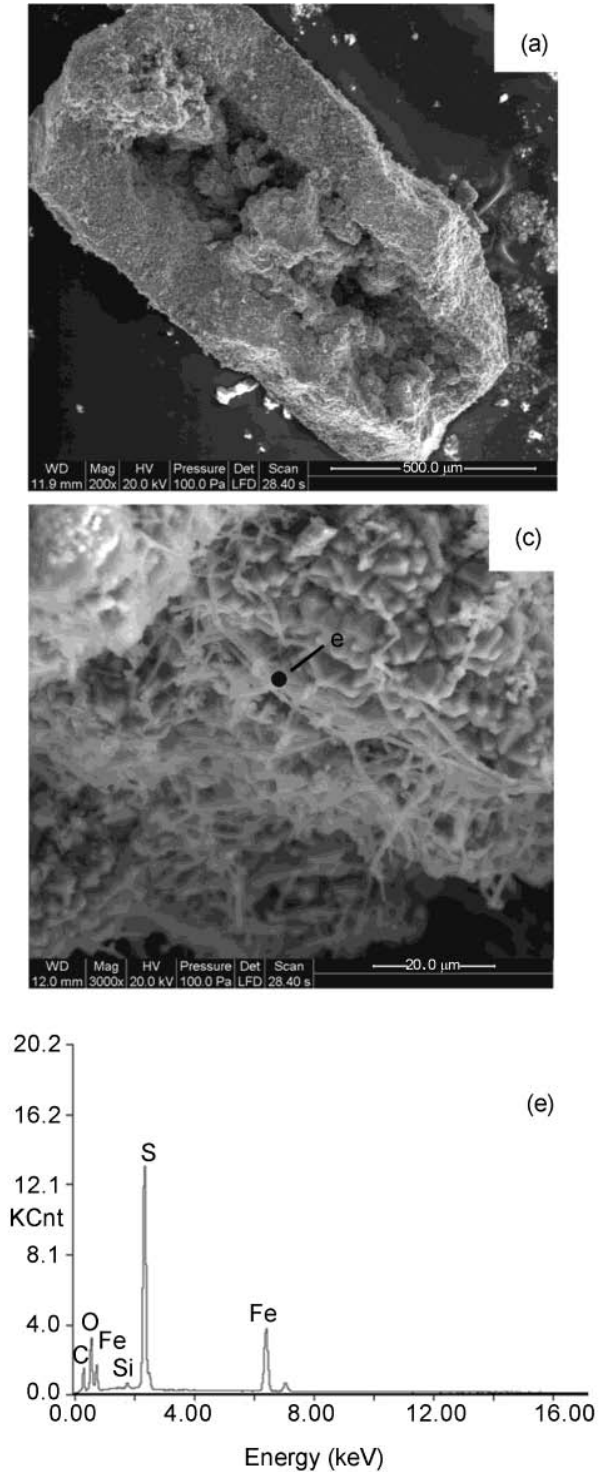
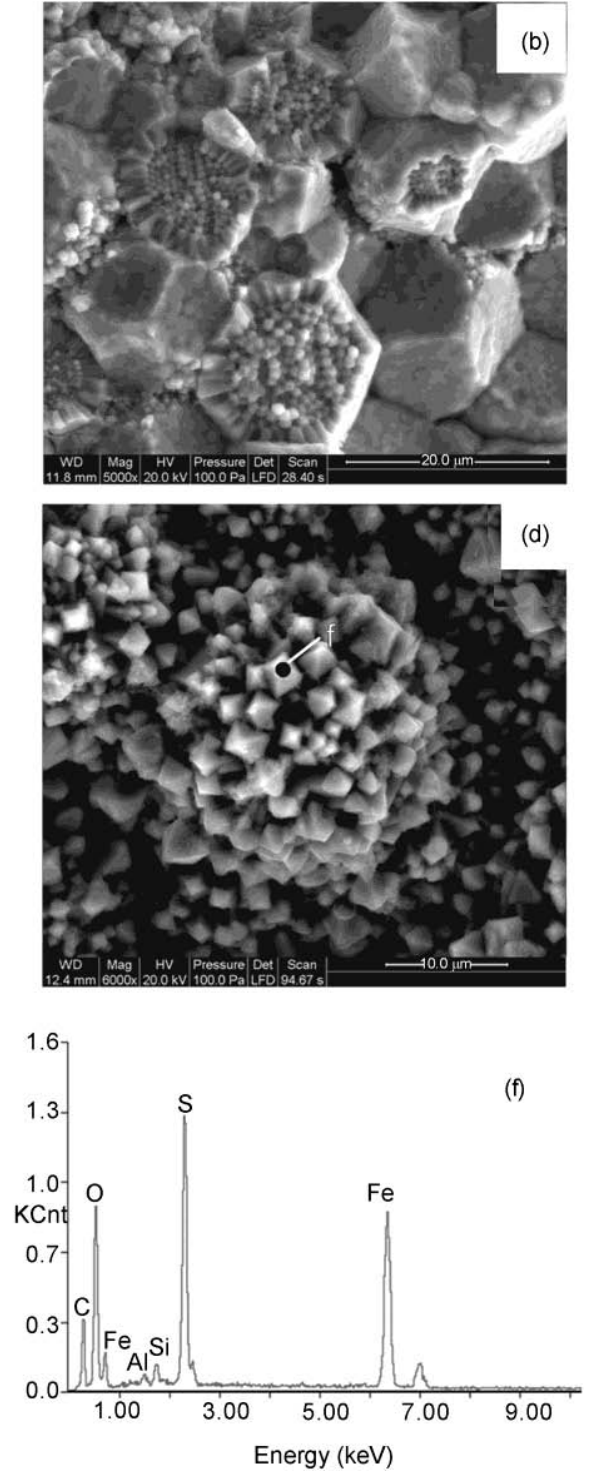

图 2 台西南盆地管状黄铁矿中草莓状黄铁矿扫描电子显微镜图片及其能谱(EDS)图

(a), (b), (d) 草莓状黄铁矿; (c) 草莓状黄铁矿表面丝状物; (e) 图 2(c)中(圆点)处的 EDS 分析结果; (f) 草莓状黄铁矿微粒(图 3(d)圆点)EDS 分析 结果. 样品号: GC10-19b

产出, 即为原生石墨, 另一种是从含 $\mathrm{C}-\mathrm{H}-\mathrm{O}$ 饱和流 体中沉淀、晚于原岩形成的后生石墨,一般呈脉状产 出. 本次研究所发现的石墨与自生管状黄铁矿共生, 矿物学研究显示其周围深海软泥中不存在石墨, 因 此这些石墨碳应来自 C-H-O 饱和流体的沉淀.

Luque 等人 ${ }^{[21 ~ 23]}$ 和 Pasteris 等人 ${ }^{[24]}$ 对产出于不同 环境下流体沉淀石墨的矿物学和有序度进行了系统 研究, 发现温度在石墨沉淀过程中起到关键作用, 要 形成高结晶度的石墨, 从流体沉淀者比变质成因者 需要更高的温度, 其原因在于高结晶度石墨在流体
中成核和生长过程需要较高的动能, 因此绝大多数 情况下, 流体沉淀的高结晶度石墨只限于高温环境 形成 ${ }^{[24]}$. 而要在低温条件下从流体中沉淀出石墨, 必须满足两个条件: (1) C-H-O 流体中的初始 C 含量 非常高, 处于过饱和状态, 因为低温下 $\mathrm{C}$ 在 $\mathrm{C}-\mathrm{H}-\mathrm{O}$ 流体中的溶解度很高 ${ }^{[25]}$; (2) 石墨的结晶度较低, 甚 至是非晶质石墨, 因为在低温 $\mathrm{C}-\mathrm{H}-\mathrm{O}$ 流体中低结晶 度石墨比高结晶度者易于成核 ${ }^{[21]}$.

天然气水合物赋存区显然属于低温环境, 温度 一般低于 $10^{\circ} \mathrm{C}^{[26]}$. 在如此低温条件下低结晶度石墨 


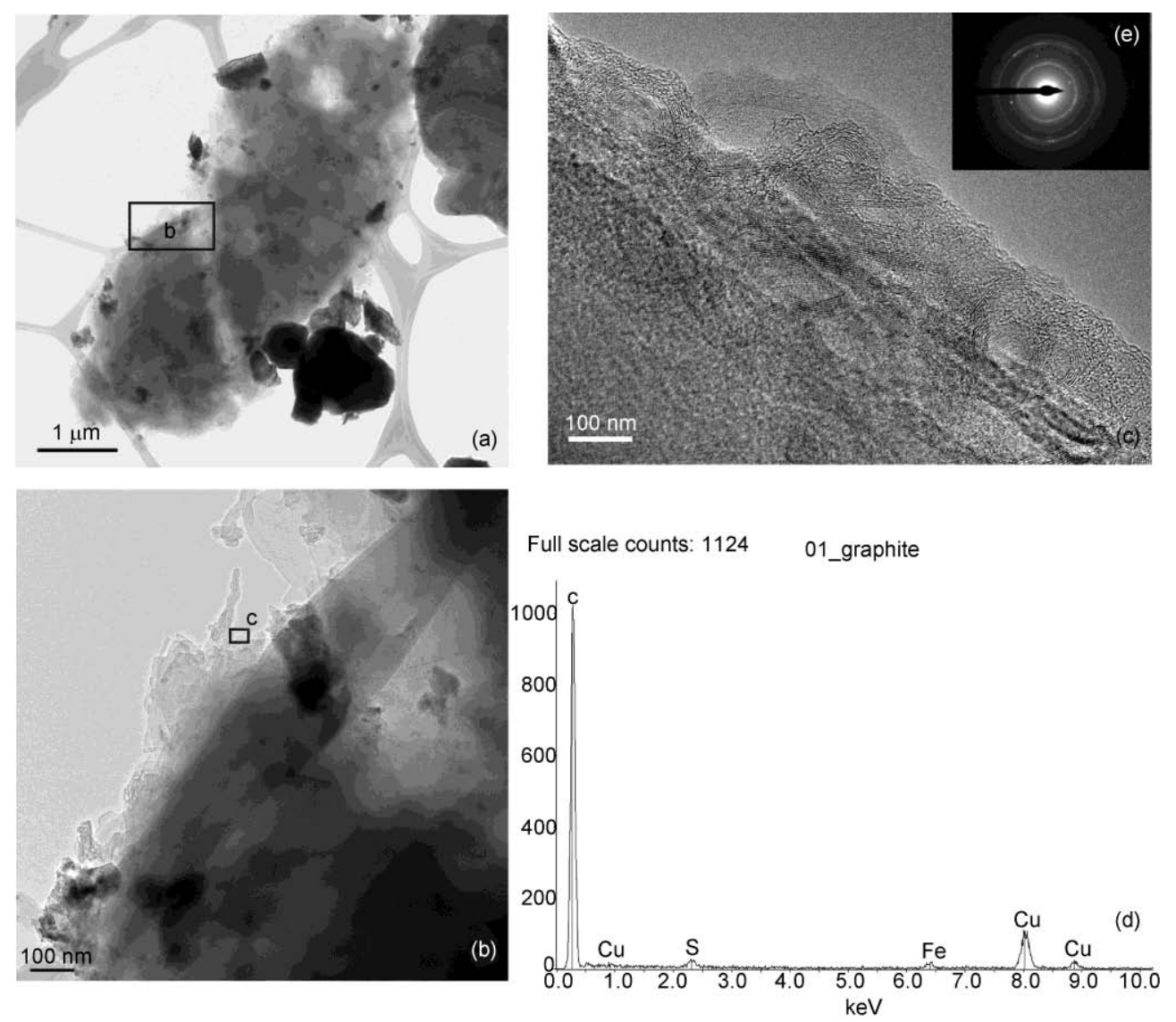

图 3 纳米级石墨碳的透射电子显微镜照片 ((a), (b), (c))及其选区能谱图(d)电子衍射花样(e) 样品号: GC10-16b

的沉淀, 显示流体中 $\mathrm{C}$ 的含量应非常高. 而在富含 $\mathrm{C}-\mathrm{H}-\mathrm{O}$ 饱和流体迁移沉淀的过程中通常存在以下化 学反应过程:

$$
\mathrm{CH}_{4}+\mathrm{O}_{2}=\mathrm{C}+2 \mathrm{H}_{2} \mathrm{O}
$$

在天然气水合物赋存区顶部, 升温或降压将导 致水合物局部分解而形成富含 $\mathrm{CH}_{4}$ 的流体:

$$
\left(\mathrm{CH}_{4}\right)\left(\mathrm{H}_{2} \mathrm{O}\right)_{6}=\mathrm{CH}_{4}+6 \mathrm{H}_{2} \mathrm{O}
$$

正如前文所述, 本次研究样品中纳米级石墨碳和似 纳米碳层与草莓状黄铁矿密切的共生关系, 显示它 们在成因上有紧密的联系. 这种纳米级的单质 $\mathrm{C}$ 可 能说明在富甲烷的流体中存在 $\mathrm{CH}_{4}$ 气体. 当富甲烷 的流体在流经草莓状黄铁矿微晶时, 与周围的氧化 剂 $\left(\mathrm{Fe}^{3+}, \mathrm{Mn}^{4+}, \mathrm{O}_{2}\right)$ 在黄铁矿的表面进行电子交换, 从 而使甲烷发生不完全氧化作用形成纳米级的石墨碳. 作为半导体的黄铁矿, 在 $\mathrm{CH}_{4}$ 转变为原子 $\mathrm{C}$ (反应 (3)) 的过程中起到催化剂的作用, 促使 $\mathrm{CH}_{4}$ 失去电子, 最 终形成 C. 事实上人工合成碳纳米管技术中, 现今比 较成熟的工业化生产方法是化学气相沉淀法, 该方
法主要原理是气化含碳物质, 使其在饱和的气相中 沉淀纳米级的碳纳米管, 在这个过程中常会使用铁、 铜、钴等金属作为催化剂 ${ }^{[27]}$. 而且这种合成也能在溶 液中进行, 只要有固体催化剂的存在 ${ }^{[28,29]}$.

本文采样的 GC-10 站位被认为是天然气水合物 潜在的远景开发区, 前人已发现了大量的黄铁矿和 碳酸盐如文石、白云石和方解石等自生矿物, 诸多 的地球化学和地球物理证据均已表明此处可能存在 天然气水合物 ${ }^{[3,4]}$. 管状黄铁矿中新发现的纳米级石 墨碳, 显示本区海底沉积物中存在大量 $\mathrm{CH}_{4}$ 过饱和 流体, 因此可以用来作为天然气水合物的又一重要 示踪性矿物. 同时, 低温环境中纳米级石墨碳的发 现对常温条件下石墨的人工合成和工业生产具有借 鉴意义.

\section{4 结论}

在南海台西南潜在水合物区 GC10 钻孔沉积物 自生管状黄铁矿中发现纳米级石墨碳, 其结晶程度 
较低, 显示它们形成于还原的 $\mathrm{CH}_{4}$ 过饱和流体的沉 淀. 草莓状黄铁矿的存在催化石墨的沉淀过程，因
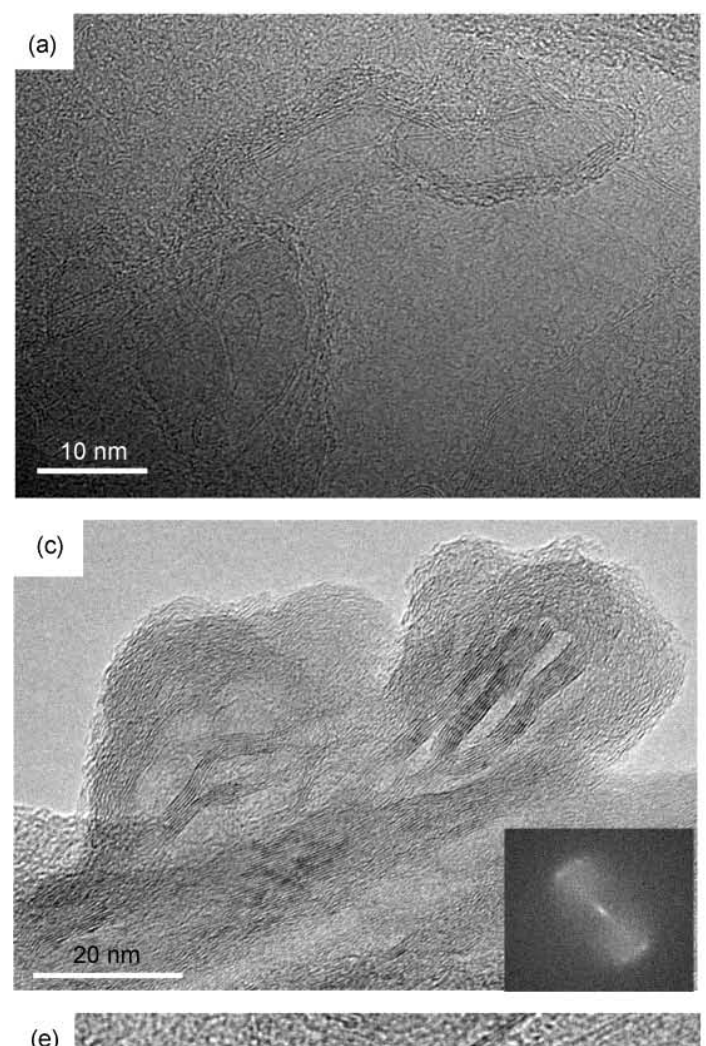

(e)

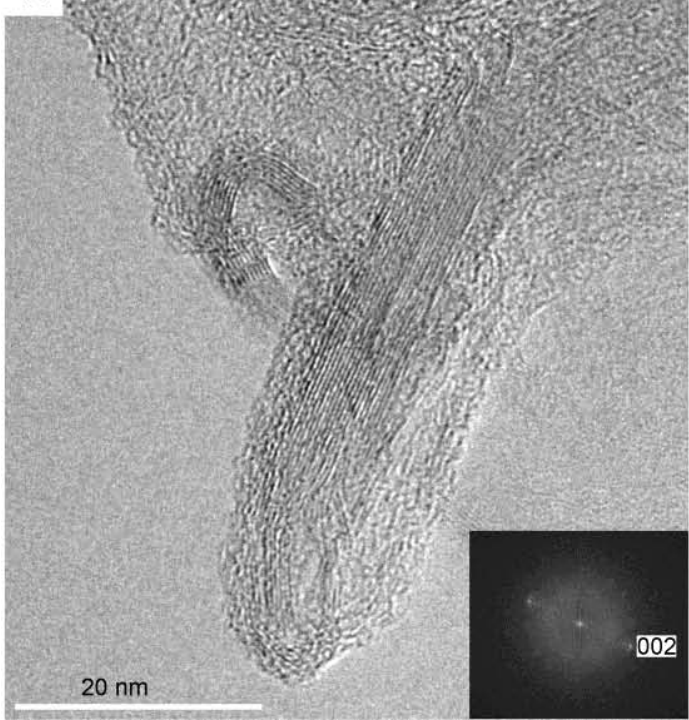

此，自生黄铁矿石墨碳包体可作为天然气水合物又 一重要的示踪矿物.
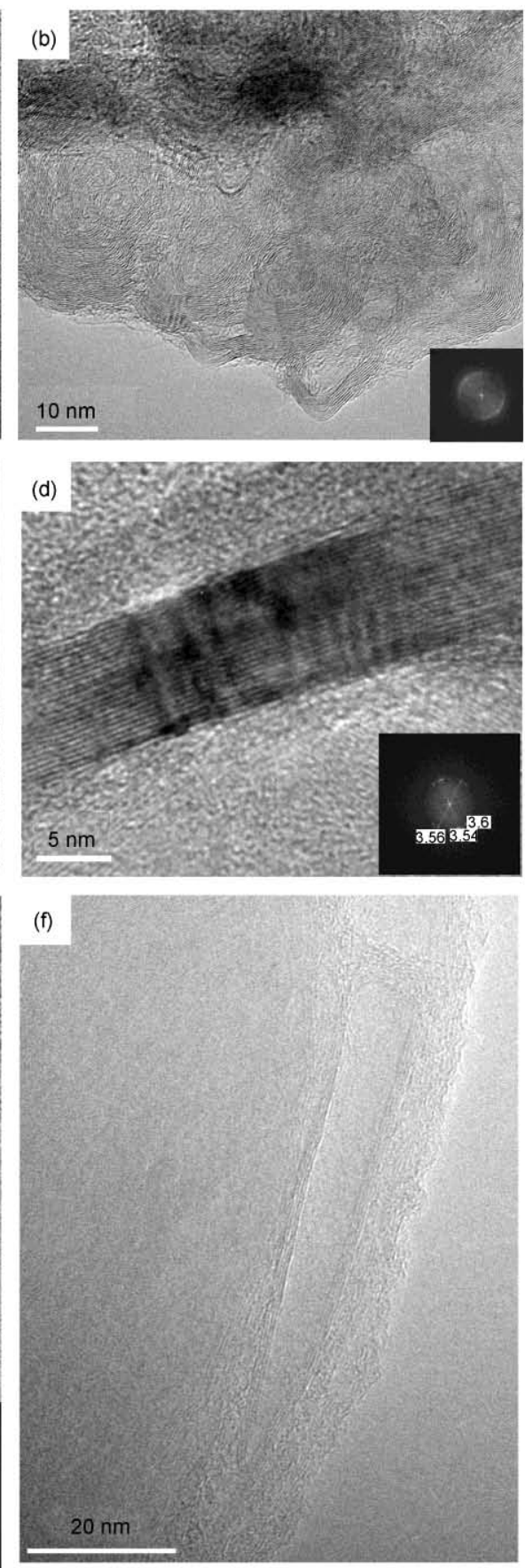

图 4 纳米级石墨碳的高分辨率透射电子显微镜(HRTEM)照片

（a) 纳米石墨碳，具环状结构; (b) 纳米级的石墨碳; (c) 生长扭曲的纳米级的石墨碳层; (d) 纳米级的石墨碳，具板状结构; (e) 纳米石墨化碳层; (f) 纳米级石墨雉. (a), (d), (e), (f)样品号为 GC10-16b; (b)和(c)样品号为 GC10-19b 


\section{参考文献}

1 Kvenvolden K A. Gas hydrates-geological perspective and global change. Rev Geophys, 1993, 31: 173-187

2 Sassen R, Roberts H H, Carney R, et al. Free hydrocarbon gas, gas hydrate, and authigenic minerals in chemosynthetic communities of the northern Gulf of Mexico continental slope:relation to microbial processes. Chem Geol, 2004, 205: 195-217

3 黄奇瑜, 简至暐. 台湾西南海域增积岩体天然气水合物研究及陆域西部麓山带甲烷来源自生碳酸钙结核地质背景比较. 见: 中国 地质学会, 编. 第六届世界华人地质科学研讨会和中国地质学会二零零五年学术年会论文摘要集. 北京: 中国地质学会, 2005.57

4 陆红锋, 陈芳, 廖志良, 等. 南海东北部 HD196A 岩心的自生条带黄铁矿. 地质学报, 2007, 81: 519-525

5 王宏斌, 张光学, 杨木壮, 等. 南海陆坡天然气水合物成藏的构造环境. 海洋地质与第四纪地质, 2003, 23: 81-86

6 Wu S, Zhang G, Huang Y, et al. Gas hydrate occurrence on the continental slope of the northern South China Sea. Mar Petrol Geol, 2005, 22: $403-412$

7 Huang C Y, Chien C W, Zhao M X, et al. Geological study of active cold seeps in the syn-collision accretionary prism kaoping slope off SW Taiwan. Terr Atmos Ocean Sci, 2006, 17: 679-702

8 Liu C S, Schnürle P, Wang Y, et al. Distribution and characters of gas hydrate offshore of Southwestern Taiwan. Terr Atmos Oc ean Sci, 2006, 17: 615-644

9 Mcdonnell S L, Max M D, Cherkis N Z, et al. Tectono-sedimentary controls on the likelihood of gas hydrate occurrence near Taiwan. Mar Petrol Geol, 2000, 17: 929-936

10 张志杰, 于兴河, 刘博. 我国台西南附近构造沉降与沉积作用对气水合物成藏的可能控制. 天然气地球科学, 2004,15: 655-659

11 吴必豪, 张光学, 祝有海, 等. 中国近海天然气水合物的研究进展. 地学前缘, 2003, 10: 177-189

12 祝有海, 吴必豪, 卢振权. 中国近海天然气水合物找矿前景. 矿床地质, 2001, 20: 174-180

13 孙春岩, 牛滨华, 王宏语, 等. 西沙海槽研究区天然气水合物地球化学勘探及成藏模式研究. 地学前缘, 2005, 12: 243-251

14 Zhang H, Yang S, Wu N, et al. Successful and surprising results for China's first gas hydrate drilling expedition. Fire Ice Newslett, 2007. 6-9

15 Guo T M, Wu B H, Zhu Y H, et al. A review on the gas hydrate research in China. J Petrol Sci Eng, 2004, 41: 11-20

16 黄永样, Suess E, 吴能友. 东沙海域东北天然气水合物存在的地质背景与证据. 见: 海峡两岸天然气水合物学术研讨会论文集. 台 南: 成功大学, 2005. 3-4

17 Wang S, Yan W, Song H. Mapping the thickness of the gas hydrate stability zone in the South China Sea. Terr Atmos Ocean Sci, 2006, 17: $815-828$

18 张美, 孙晓明, 芦阳, 等. 南海台西南盆地自生管状黄铁矿及其对天然气水合物的指示意义. 矿物学报, 2009, 29(Suppl): 385-386

19 冯有利, 于立竟. 新疆苏吉泉石墨矿床中的纳米石墨雉的结构表征. 硅酸盐通报, 2007, 26: 9-12

20 Lin S, Huang K M, Chen S K. Organic carbon deposition and its control on iron sulfide formation of the southern East China Sea continental shelf sediments. Cont Shelf Res, 2000, 20: 619-635

21 Luque F J, Ortega L, Barrenechea J F, et al. Deposition of highly crystalline graphite from moderate-temperature fluids. Geology, 2009, 37: $275-278$

22 Luque F J, Pasteris J D, Wopenka B, et al. Natural fluid-deposited graphite: mineralogical characteristics and mechanisms of formation. Am J Sci, 1998, 298: 471-498

23 Luque F J, Rodas M. Constraints on graphite crystallinity in some Spanish fluid deposited occurrences from different geologic settings. Mineral Depos, 1999, 34: 215-219

24 Pasteris J D, Chou I M. Fluid-deposited graphitic inclusions in quartz: Comparison between KTB (German continental deep-drilling) core samples and artificially re-equilibrated natural inclusions. Geochim Cosmochim Acta, 1998, 62: 109-122 Pasteris J D. Causes of the uniformly high crystallinity of graphite in large epigenetic deposits. J Metamorphic Geol, 1999, 17: 779-787 Kvenvolden K A. Methane hydrate-a major reservoir of carbon in the shallow geosphere. Chem Geol, 1988, 71: 41-51 Lee C J, Park J, Yu J. Catalyst effect on carbon nanotubes synthesized by thermal chemical vapor deposition. Chem Phys Lett, 2002, 360: 250-255 Libera J, Gogotsi Y. Hydrothermal synthesis of graphite tubes using Ni catalyst. Carbon, 2001, 39: 1307-1318 Hata K, Futaba D N, Mizuno K, et al. Water-assisted highly efficient synthesis of impurity-free single-waited carbon nanotubes. Science, 2004, 306: 1362-1364 